\title{
A atuação do psicólogo no ensino público do Estado do Paraná
}

\author{
Patrícia Vaz de Lessa \\ Marilda Gonçalves Dias Facci
}

\begin{abstract}
Resumo
Este artigo objetiva apresentar dados da pesquisa que teve como finalidade identificar e analisar as práticas desenvolvidas pelos psicólogos da rede pública do Estado do Paraná frente às queixas escolares. Discorreremos brevemente sobre a constituição histórica da atuação do psicólogo escolar, pautada inicialmente por uma visão tradicional, que foi alvo de críticas por volta de 1980, culminando com uma atuação baseando-se em pressupostos da Psicologia Histórico-Cultural, fundamentada no marxismo; em seguida, apresentaremos alguns dos dados dos questionários, caracterizando a primeira fase da pesquisa. Dentre os principais resultados, salientamos que os profissionais vivenciam um momento de transição, pois percebemos, ao longo da pesquisa, que existe um movimento de avanço nas práticas e na compreensão das queixas escolares, evidenciadas nas ações que envolvem todo o contexto escolar. Finalizando, destacamos a importância da perspectiva da Psicologia Histórico-Cultural, considerando que ela trabalha em prol do processo de humanização e pode contribuir para auxiliar os psicólogos na compreensão do homem concreto.
\end{abstract}

Palavras-chave: Psicologia Escolar, atuação do psicólogo, Psicologia histórico-cultural.

\section{Psychologist performance in Paraná's public schools}

\begin{abstract}
In this article we present data from research that aimed at identifying and analyzing the practices developed by psychologists in public schools in the state of Paraná. We discuss, briefly, the historical constitution of the school psychologist and then show how it was initially supported by a traditional point of view. It was criticized in the 1980's, resulting in a performance based on assumptions of the Cultural-Historical Psychology, grounded on Marxism. Later we reveal some data from the questionnaires, characterizing the first phase of the research. We emphasize the fact that professionals go through a transitional period, as we noticed throughout the research that there is an ongoing movement towards practices and understanding of school complaints pointed out in the actions that involve the school context. Finally, we highlight the importance of the Cultural- Historical Psychology, taking into consideration that it favors the humanization process and may contribute to assist psychologists to a better understanding of man.
\end{abstract}

Keywords: School Psychology, psychologist performance, historic-cultural psychology.

\section{La actuación del psicólogo en la enseñanza pública del Estado de Paraná}

\section{Resumen}

Este artículo tiene el objetivo de presentar datos de una investigación que tuvo como finalidad identificar y analizar prácticas desarrolladas por psicólogos de la red pública del Estado de Paraná frente a quejas escolares. Se discurrirá brevemente sobre la constitución histórica de la actuación del psicólogo escolar, inicialmente guiada por una visión tradicional, blanco de críticas alrededor de 1980, culminando con la actuación con base en supuestos de la Psicología Histórico-Cultural, fundamentada en el marxismo. En seguida, se presentarán algunos de los datos de los cuestionarios, caracterizando la primera fase da investigación. Entre los principales resultados, se salienta que los profesionales viven un momento de transición, pues se percibe, a lo largo de la investigación, que existe un movimiento de avance en las prácticas y en la comprensión de las quejas escolares, evidenciadas en las acciones que envuelven todo el contexto escolar. Finalizando, se destaca la importancia de la perspectiva da Psicología Histórico-Cultural, considerando que trabaja a favor del proceso de humanización y puede contribuir para auxiliar los psicólogos en la comprensión del hombre concreto.

Palabras Clave: Psicología Escolar, actuación del psicólogo, Psicología histórico-cultural. 


\section{Introdução}

"A escola está em crise". Esta é uma afirmação que nos leva a avaliar as contradições existentes entre uma escola que deveria ensinar e uma sociedade que, embora na aparência defenda o conhecimento, na essência, nem sempre garante o acesso ao conhecimento a todos os alunos. Consideramos que este seja um dos elementos significativos para uma investigação acerca da atuação do psicólogo escolar frente às queixas escolares. É sobre esse contexto escolar e o trabalho do psicólogo que surgiu o interesse pela pesquisa que foi apresentada ao Programa de Pós-Graduação em Psicologia da Universidade Estadual de Maringá, cujos resultados serão apresentados neste artigo. Nosso objetivo, portanto, é discorrer sobre as práticas desenvolvidas pelos psicólogos na rede pública do Estado do Paraná, além de examinar como ocorre o processo de atendimento às queixas escolares no grupo investigado.

A pesquisa que vamos relatar no artigo faz parte de um projeto de maior abrangência, que teve seu início em 2008, intitulado $A$ atuação do psicólogo na rede pública de educação frente à demanda escolar: concepções, práticas e inovações, coordenado pela Prof ${ }^{a}$ Dra. Marilene Proença Rebello de Souza, da Universidade de São Paulo. A pesquisa teve com finalidade analisar a atuação do psicólogo escolar nos seguintes estados brasileiros: São Paulo, Minas Gerais, Bahia, Rondônia, Santa Catarina, Acre e Paraná ${ }^{1}$. No Paraná, tivemos o inicio da pesquisa em $2008^{2}$, passando por duas fases: os questionários e as entrevistas.

Para este artigo, propomos a apresentação dos dados dos questionários. No entanto, antes da exposição desses dados, vamos situar, sucintamente, o desenrolar da história da Psicologia Escolar no Brasil a partir de três momentos: o primeiro deles caracterizado por uma intervenção influenciada pela educação, medicina e psicometria; o segundo perpassado por questionamento ao modelo clínico e naturalizante na atuação, em uma concepção crítica de atuação; e o terceiro configurado na proposta de intervenção pautada na Psicologia Histórico-Cultural, de base marxista, concepção que buscamos defender neste trabalho.

\section{A atuação do psicólogo escolar - um pouco de história}

Conforme anuncia Antunes (2007), desde os tempos da colônia no Brasil, os fenômenos psicológicos foram preocupação presente nas diferentes áreas do saber, presente nas produções advindas de instituições como faculdades de

\footnotetext{
1 A pesquisa desenvolvida na USP contou com apoio de doutorandos e bolsistas de graduação, além da coordenação em cada Estado. No Estado do Paraná, recebemos subsídios da Fundação Araucária - Apoio ao desenvolvimento científico e tecnológico do Paraná.

2 A equipe responsável pela coleta de dados no Estado do Paraná era coordenada pela Profa. Dra. Marilda Gonçalves Dias Facci e composta pelas seguintes pesquisadoras: $\mathrm{Prof}^{\mathrm{a}}$. $\mathrm{Dr}^{\mathrm{a}}$. Zaira de Fátima Rezende Gonzales Leal, Profa. Dra Sonia Mari Shima Barroco e por Valéria Garcia da Silva - aluna do Programa de Pós-Graduação em Psicologia da Universidade Estadual de Maringá.
}

Medicina, hospícios, escolas e seminários. Tal fato, segundo a referida autora, contribuiu para o desenvolvimento da Psicologia nas áreas de Medicina e Educação, sendo influenciada pelos avanços dos estudos psicológicos na Europa.

Historicamente, a relação da Psicologia com a Pedagogia tem implicações fundamentais no Brasil, pois, conforme afirma Antunes (2007), estão intimamente ligadas ao pensamento escolanovista iniciado no Brasil no século XIX e com sua efetiva explicitação e consolidação no século XX. Coadunando com Antunes (2007), mencionamos Yazlle (1997) ao anunciar claramente as duas vertentes que contribuíram para as práticas exercidas pelos psicólogos nas instituições escolares no Brasil: o Movimento da Escola Nova e a Medicina com sua concepção higienista.

A história da Psicologia, na área da Educação, está vinculada à história da Educação e às demandas histórico-sociais que foram definindo as intervenções dos psicólogos no âmbito educacional. Já na Escola Nova, que foi elaborada em contraposição à Escola Tradicional por volta de 1930, pode-se observar que a Psicologia se faz presente enquanto fundamento, a partir das ideias defendidas por Jean Piaget. Também colaborou, dando base científica, a Pedagogia Tecnicista, por volta de 1970, a partir dos estudos desenvolvidos na Análise Experimental do Comportamento. Mais recentemente, podemos observar a influência das teorias psicológicas na Educação com o Construtivismo, a partir do final da década de 1980, retomando ideias da Epistemologia Genética de Jean Piaget.

Facci (2004), ao fazer um paralelo entre as tendências pedagógicas que guiaram a educação no Brasil e a atuação do psicólogo escolar, explicita essa relação nas tendências pedagógicas aqui anunciadas, chegando até o momento, resgatando pressupostos da Psicologia Histórico-Cultural e da Pedagogia Histórico-Crítica. Portanto, é inegável que as tendências pedagógicas foram sendo fundamentadas por teorias psicológicas, possibilitando a vinculação entre Psicologia e Educação e contribuindo para a inserção do psicólogo na escola.

Além dos modelos pedagógicos, vemos, conforme menciona Yazlle (1997), a forte presença dos modelos biológicos e físicos de ciência predominantes na Medicina em laboratório de Psicologia, criados para estudar aspectos do comportamento humano e explicar as patologias, desvios ou desajustes. Desde o início, a Psicologia declara-se comprometida com "[...] um projeto social burguês e com as regras sociais decorrentes do capitalismo" (Yazlle, p. 14). Esta ciência foi se inserindo na escola para explicar como a criança aprende, e o psicólogo, por sua vez, foi pautando sua ação, guiado pela Medicina e pela Psicometria.

Vários médicos pioneiros dedicaram-se à Psicologia, o que contribuiu com a formação de numerosos pesquisadores, desde a Psicofisiologia até a Psicologia Social. Segundo Yazlle (1997), a preocupação predominante estava em criar laboratórios de Psicologia para estudar aspectos do comportamento humano e explicar as patologias, desvios ou desajustes. A autora menciona que a Liga Brasileira de Higiene Mental, criada no Rio de Janeiro em 1922, primeiro órgão 
autônomo de Psicologia no Brasil, manteve a forte influência da Medicina na Educação por longo tempo; influência esta intensificada após a Segunda Guerra Mundial. O movimento direcionou seu olhar para a escola e as instituições de atendimento à infância no sentido de fazer prevenção de desajustes e adaptação dos indivíduos "[...] em uma perspectiva diagnóstica, clínica e individualizante [...]" (Yazlle, 1997, p. 23).

A Psicometria viria em auxílio da Psicologia para compreender as dificuldades de aprendizagem das crianças. Exemplificando essa condição, encontramos Patto (1984), ao afirmar que a origem dos livros-texto de Psicologia Escolar encontra-se nos trabalhos de Galton e Binet. Esses autores foram convidados, na França, a explicar por que um elevado número de alunos, filhos da classe trabalhadora, estava fracassando na escola. Estavam expressamente interessados na mensuração das diferenças individuais por meio da seleção dos mais capazes, utilizando-se de instrumentos de medida de inteligência e de personalidade, que se tornaram o principal instrumento de trabalho do psicólogo. Segundo Patto (1984, p. 99), a primeira função desempenhada pelos psicólogos junto aos sistemas de ensino, "[...] foi a de medir habilidades e classificar crianças quanto à capacidade de aprender e de progredir pelos vários graus escolares".

Essa característica da Psicologia mais voltada para o aluno, atrelada à utilização dos instrumentos de medição, marcou o início do trabalho da Psicologia no contexto escolar por volta de 1940, conforme encontramos em Patto (1984), Vasconcelos (1996) e Yazlle (1997). Desta forma, para Maluf (1994), no início da profissão, os psicólogos tinham a característica de técnico, com uma atuação voltada mais para o aspecto curativo, no qual buscava resolver os problemas de aprendizagem e de rendimento escolar utilizando os testes de inteligência e encaminhando os alunos para os mais diversos tipos de tratamento. Segundo a autora, mesmo quando a atuação passou a ter certo caráter preventivo, o psicólogo teve dificuldades de se afastar totalmente do modelo clínico, continuando a tratar os problemas de forma centrada no indivíduo. Essas práticas deixavam de considerar que os problemas são de origem multideterminada, que são influenciados pela forma como a sociedade está estruturada. O foco do trabalho estaria centrado no aspecto psicológico no qual o olhar se volta para o diagnóstico dos problemas dos alunos, e a Psicologia, neste momento, explicava o fracasso escolar estritamente relacionado aos déficits dos alunos ou de sua condição precária de vida, guiada pela Teoria da Carência Cultural.

Yazlle (1997) considera que essa Psicologia praticada até então vinha se caracterizando pela "psicologização das questões educacionais, originando práticas individualistas e ajustatórias com ênfase nos processos de aprendizagem e nos processos remediativos - modelo médico - como solução dos chamados problemas escolares" (p. 35). Essa concepção levou vários profissionais a questionarem o modelo de atuação que estava sendo realizado, contribuindo para o desenvolvimento, a partir da metade da década de 1970, de uma Psicologia Escolar Crítica que, segundo Maluf (2006), tinha o objetivo de compreender "[...] os determinan- tes históricos e sociais da formação e da atuação do psicólogo escolar" (p. 135).

Meira (2000) relata que foi nesse período que se iniciaram as discussões sobre os caminhos e descaminhos da Psicologia Escolar, marcando o fato com a publicação, em 1984, do livro Psicologia e Ideologia - uma introdução crítica à Psicologia Escolar, de Maria Helena de Souza Patto. Patto se tornou uma referência para todos os profissionais que buscavam um novo sentido e uma nova perspectiva de atuação, colocando-se a serviço de um processo efetivo de democratização educacional e social. É neste momento histórico que foi se estruturando uma visão crítica de Psicologia e percebeu-se não ser mais possível ignorar a importância e o compromisso da Psicologia em efetivar uma ruptura com os interesses das classes dominantes e construir novos pressupostos gerais para a área.

Machado (2010) enfatiza que a postura do profissional em uma atuação crítica pode produzir outros efeitos, pois:

[...] ao agir nas relações estabelecidas na escola, trabalhar com as representações dos professores e somar, com os saberes da psicologia, no levantamento de hipóteses em relação à produção das dificuldades de leitura e escrita e das questões atitudinais pode-se ampliar o campo de análise e, portanto, as possibilidades de intervenção em relação aos problemas presentes no processo de escolarização (Machado, 2010, p. 29).

O foco, portanto, passa a ser o processo de escolarização e não o aluno. Nesta mesma direção, encontramos Proença (2002) ao se referir às queixas escolares, afirmando que as avaliações e intervenções realizadas, na grande maioria das vezes, culpabilizavam as crianças por não aprenderem, não considerando o processo de escolarização que produz a queixa. Na perspectiva de um olhar crítico, considera-se que os rótulos impostos aos alunos como aqueles que são desinteressados, apáticos, entre outras adjetivações, e que os acompanham vida afora podem provocar a cristalização dos personagens na escola, não possibilitando conhecer os fatores multideterminados que levam ao não aprendizado. Concordamos com as autoras ao defender que a intervenção com um enfoque crítico questiona a culpa imposta ao aluno pelo fracasso e direciona sua análise para as questões mais amplas, incluindo a qualidade do ensino e os preconceitos e estereótipos existentes no contexto escolar com relação às crianças pobres.

Machado e Souza (1997) citam que as práticas que objetivaram esses "alunos-problema" estão entre "[...] psicólogos fazendo avaliações diagnósticas para encaminhamento, professores entendendo os problemas das crianças como algo individual ou familiar, a exigência de um laudo psicológico para a criança estar na classe especial” (p. 37). Souza (2007) complementa que a escola deve ser incluída na investigação e na intervenção da queixa ampliando a compreensão da construção desta. Neste sentido, concordamos com Moysés e Collares (1997) ao afirmar que uma proposta bem fundamentada, para uma avaliação adequa- 
da, envolve avaliar todas as condições das crianças, analisando não somente o que a criança não tem, não sabe, mas entendendo o que ela sabe fazer, o que ela gosta de fazer e o que pode aprender a partir de então. Direcionada a atuação para esses pressupostos, o profissional não terá espaço para a utilização única e exclusiva dos testes psicológicos e laudos, assim, a utilização de testes não seria a forma mais recomendada a ser desenvolvida pelos autores e profissionais com uma visão mais ampla do processo de avaliação. Souza (2007) considera que as críticas na área da Psicologia Escolar necessitam buscar a superação de uma atuação pautada na visão psicométrica com as contribuições de laudos psicológicos; nas explicações ao fracasso baseadas na teoria da carência cultural; e no modelo clínico de atuação no atendimento à queixa escolar.

Diante dessas defesas, podemos observar o movimento de mudanças e transformações teórico-metodológicas que a Psicologia vem promovendo ao longo de sua história: de um modelo tradicional, baseado em uma intervenção clínica, medicalizante, utilizando a psicometria como instrumento de avaliação, parte para uma visão mais ampla do processo de escolarização e da sociedade.

Continuando neste movimento de crítica à Psicologia Tradicional, com ênfase naturalizante e biologizante, a partir da década de 1990, outra forma de atuação passa a ser desenvolvida, agora tomando como referência pressupostos marxistas, pautada na Psicologia Histórico-Cultural a partir dos estudos desenvolvidos pela Escola de Vigotski e pela Pedagogia Histórico-Crítica, elaborada por Dermeval Saviani. Os pressupostos da Psicologia Histórico-Cultural primam pela superação de uma Psicologia guiada pela lógica formal, contribuindo para compreender os fenômenos escolares e o desenvolvimento do psiquismo a partir da lógica dialética. Nesta perspectiva teórica, é o historicismo que engendra a compreensão do desenvolvimento do psiquismo. A Pedagogia Histórico-Crítica, por sua vez, traz para o centro do debate a compreensão de que a escola está vinculada à forma como a sociedade está organizada, aos interesses do capital, e defende a socialização do conhecimento, contribuindo para o processo de humanização dos alunos (Saviani, 2003).

Conforme enfatiza Meira (2003), o momento de emancipação da Psicologia na direção de uma postura crítica se deu da necessidade de analisar e compreender a educação escolar no Brasil a partir das condições histórico-sociais e de assumir um novo posicionamento político, bem como o papel social da Psicologia. Para Meira (2000), que se pauta em pressupostos da Psicologia Histórico-Cultural, uma avaliação crítica da Educação e da sua função e o conhecimento amplo das múltiplas determinações compõem a condição necessária para o psicólogo delimitar seu espaço histórico e social, buscando elementos e caminhos possíveis para a transformação neste espaço escolar. Neste sentido, a autora sintetiza a concepção crítica, afirmando que uma concepção ou teoria é crítica à medida que:

Tem condições de transformar o imediato em mediato; negar as aparências sociais e as ilusões ideológicas; apanhar a totalidade do concreto em suas múltiplas determinações e articular essência/aparência, parte/todo, singular/universal e passado/presente, compreendendo a sociedade como um movimento de vir a ser. (Meira, 2000, p. 40)

Tanamachi e Meira (2003, p.23), nesta mesma linha que vimos traçando, também sinalizam alguns fatores que caracterizam uma concepção crítica em Psicologia e definem que a Psicologia desenvolvida a partir do Materialismo Histórico Dialético é marcada por princípios que compreendem o mundo objetivo como histórica e socialmente determinado e que "[...] não partem, portanto, de um errôneo primado ontológico do indivíduo, mas das relações sociais para chegar à 'biografia' do indivíduo e retornar ao social; não reduzem o conceito de indivíduo à descrição das características de indivíduos em geral (indivíduos empíricos)".

Concordamos com Meira e Tanamachi e também defendemos que a atuação da Psicologia na escola com pressupostos Marxianos/Vigotskianos é uma proposta que leva em conta o processo ensino-aprendizagem e de humanização a que se propõe. Leontiev (1978) defende a ideia de que é pela educação que o homem se humaniza, que ele precisa se apropriar dos bens culturais para se tornar humanizado. Vigotski (2000) deixa claro o quanto a aprendizagem promove o desenvolvimento das funções psicológicas superiores, tais como memória lógica, abstração e atenção concentrada, entre outras funções. Para o autor, a escola deve trabalhar com conhecimentos científicos e, neste processo, conforme anuncia Facci (2004), o professor faz a mediação entre o conhecimento curricular e o aluno, provocando transformação nas funções psicológicas superiores dos alunos e, consequentemente, na forma de conhecer a realidade. Markus (1974) afirma que a escola, quando leva o aluno à apropriação de novos conceitos, contribui para que ele obtenha um maior conhecimento da realidade, porque:

penetra na essência interna dos objetos, já que a natureza dos mesmos não se revela na contemplação direta de um ou outro objeto isolado, senão por meio dos nexos e relações que se manifestam na dinâmica do objeto, em seu desenvolvimento vinculado a todo o resto da realidade (Vygotski, 1996, p. 79).

Nesta linha de atuação pautada na Psicologia Histórico-Cultural, fundamentada no materialismo histórico e dialético, o psicólogo passa a entender o homem como "síntese das relações sociais", conforme destaca Saviani (2004). O homem passa a ser entendido como um sujeito concreto, que carrega, em seu psiquismo, marcas da história da humanidade e da sua própria história, isto é, um homem que resulta da filogênese e da ontogênese e que, para se humanizar, necessita se apropriar dos bens materiais e culturais já produzidos.

Tanamachi e Meira (2003), pautadas nos pressupostos do pensamento crítico expressos na Pedagogia Históri- 
co-Crítica e na Psicologia Sócio-Histórica, defendem que o objeto do psicólogo em uma instituição de ensino é:

[...] o encontro entre os sujeitos e a educação e a finalidade central de seu trabalho deve ser contribuir para a construção de um processo educacional que seja capaz de socializar o conhecimento historicamente acumulado e de contribuir para a formação ética e política dos sujeitos (Tanamachi e Meira, 2003, pp. 42-43).

Assim, ao delimitar a área de intervenção mais importante em que a Psicologia pode contribuir, surge sua contribuição na direção da escola para que cumpra sua função de socialização dos conhecimentos já produzidos pelos homens, conforme defende Saviani (2003). Segundo Tanamachi e Meira (2003), partindo de uma concepção vigotskiana, o psicólogo pode contribuir para desvelar a ideologia implícita nas concepções que cristalizam a defesa de que os problemas educacionais estão no interior dos próprios alunos, combatendo, assim, as explicações que "psicologizam" esses problemas educacionais.

Consideramos que os pressupostos da Psicologia Histórico-Cultural podem ajudar na superação de uma visão tradicional que, muitas vezes, dirige a prática dos psicólogos, influenciados por uma visão calcada no ideário liberal. Ao considerar o homem como um sujeito histórico, que produz e é produzido pelas condições materiais, essa vertente da Psicologia pode ser uma grande aliada na defesa da compreensão da formação humana no processo educativo.

Fizemos, neste primeiro item do artigo, uma sucinta exposição da trajetória da Psicologia Escolar, marcada inicialmente por uma visão tradicional, naturalizante e clínica em um primeiro momento; por uma crítica a essa visão, por volta de 1980, com a proposição de uma forma mais ampla da compreensão das queixas escolares; chegando, em um terceiro momento, a uma visão marxista da atuação do psicólogo, com base na Psicologia Histórico-Cultural. Como veremos na segunda parte do texto, que trata dos dados coletados por meio de questionários respondidos por psicólogos, esses vários momentos estão povoando a prática do psicólogo escolar.

\section{A pesquisa com os psicólogos}

No Estado do Paraná, há 32 Núcleos Regionais de Ensino $^{3}$ - NRE e oficialmente 395 municípios estão vinculados a esses Núcleos. Para o desenvolvimento da pesquisa, inicialmente, foram mantidos contatos por telefone ou e-mails com os esses NRE e com as cidades para identificar aquelas que tinham, em seu quadro de profissionais, o psicólogo atuando na educação; no total, 350 cidades participaram da

3 Os Núcleos Regionais de Ensino são unidades que estão diretamente ligadas à Secretaria de Estado da Educação do Paraná, atuando em várias regiões do Estado. Eles acompanham a implantação e execução das políticas educacionais do Governo do Estado do Paraná no âmbito das escolas que fazem parte de sua jurisdição. pesquisa. Uma vez localizados os psicólogos, estabelecemos contato com por meio de telefone e/ou e-mail a fim de apresentar os objetivos da pesquisa e fazer o convite para responder ao questionário para levantamento de dados.

Das 350 cidades com as quais entramos em contato, localizamos 291 municípios que têm psicólogo. Como algumas cidades possuem mais de um psicólogo, no total, foram identificados 385 psicólogos. Na pesquisa, enviamos os questionários para todos esses profissionais. O roteiro continha questões sobre o tempo de trabalho do profissional na equipe, seu cargo, formação e, de modo amplo, sua filiação teórica e modalidades de atuação de que se utiliza para responder às demandas escolares. No total, 95 psicólogos preencheram o questionário ${ }^{4}$ dando-nos o retorno. Os dados coletados nos questionários foram submetidos à analise estatística por meio do Software Statistical Package for Social Science (SPSS) versão 14.

A primeira parte do questionário caracterizou-se por perguntas fechadas, englobando respostas objetivas que deveriam ser assinaladas pelo psicólogo; a segunda parte foi constituída de perguntas abertas.

Ao finalizar a coleta de dados por meio dos questionários, chegamos aos seguintes dados, que nos permitem caracterizar o grupo de profissionais: a maior parte dos participantes era do sexo feminino (91,6\%); a média de idade era de 35 anos e 4 meses; a média de tempo no cargo entre os profissionais foi de 5 anos e 4 meses; a média do tempo de formação indica um índice de 8 anos e 1 mês; o cargo desempenhado, conforme contrato estabelecido com a Secretaria de Educação, pela maioria dos profissionais é de psicólogo (79,8\%), seguida do cargo de professor $(13,5 \%)$; a função desempenhada que se evidencia com destaque é a de psicólogo, com $58,5 \%$ das respostas, seguido do psicólogo escolar, com um índice de $24,5 \%$; enquanto instituição formadora, encontramos o maior índice nas instituições particulares, com $60 \%$ das respostas, seguidas da pública, com $33,7 \%$; quanto aos cursos realizados pelos pesquisados, a especialização e o aprimoramento aparecem com maior índice de respostas, $86,2 \%$; a área dos cursos realizados que mais se destaca é a área de Educação, com 42,4\% das respostas; os níveis de ensino em que os profissionais atuam e merecem destaque são: Infantil e Fundamental, com 53,7\% das respostas, em seguida, aparece o nível Fundamental, com 14,7\%, e, por último, a Educação Inclusiva, com uma representatividade nos dados de $10,5 \%$ das respostas. Não nos deteremos a uma análise destas respostas, apresentamos os dados mais no sentido de caracterizar o grupo de psicólogos; delimitaremos a discussão para as respostas fornecidas nas questões abertas.

\footnotetext{
4 Ressaltamos que os questionários foram enviados via e-mail para todos os psicólogos localizados. O roteiro utilizado para a coleta das informações seguiu o modelo traçado pela pesquisadora $\operatorname{Prof}^{\mathrm{a}} \mathrm{Dr}^{\mathrm{a}}$ Marilene Proença Rebello de Souza, da Universidade de São Paulo - USP, elaborado para coleta de dados da pesquisa anteriormente citada. Para a análise dos dados coletados nos questionários, também utilizamos o modelo de análise e a categorização desenvolvida pela equipe da referida pesquisa.
} 
No quesito público alvo atendido, verificamos que a categoria que mais obteve índice de respostas foi a categoria todos na qual incluímos: pais, alunos, professores e funcionários, com $49,5 \%$ das respostas, seguido da categoria: pais, alunos e professores, com 34,7\%. Ao refletir sobre esses dados, podemos concluir que eles demonstram certa mudança na forma de intervenção, pois a Psicologia tem uma história marcada pela conduta profissional pautada em trabalhos dirigidos exclusivamente ao aluno, enfatizando sua capacidade/incapacidade individual de fazer algo e ter sucesso.

Machado e Souza (1997) defendem uma atuação que procura envolver todos aqueles que estão à volta da criança no processo educativo, promovendo, em sua prática, formas de conhecer a professora da criança, verificar como esta entende os problemas do aluno, obter informações sobre o contexto da sala de aula e obter dados sobre a história escolar, ou seja, ampliar as informações referentes à queixa envolvendo os professores, pais e toda equipe escolar possível.

Souza (2007) também defende essa forma de intervenção, na qual é possível utilizar alguns procedimentos como: orientação aos pais, encontros com as crianças ou adolescentes, interlocução com a escola e entrevistas de fechamento e acompanhamento. Assim, observando essa forma de conduzir o trabalho, a escola é incluída na investigação e na intervenção da queixa, pois, segundo Souza (2007), a escola não é a estrutura intocável. É por esse motivo que a autora se coloca em contraposição às práticas adaptacionistas, que entendem a superação da queixa escolar como uma mudança apenas da criança/adolescente portadora da queixa. Nesse sentido, encontramos, em nossa pesquisa, a postura profissional, no Paraná, que sinaliza coerência na busca para a intervenção que sai do âmbito do aluno para o envolvimento da comunidade escolar, o que consideramos um avanço, pois tínhamos, até a década de 1980, por exemplo, predominância de modelos que focam no aluno a culpa do fracasso escolar.

No item sobre a modalidade de atuação, a que mais se destacou foi institucional e clínica, com $54,3 \%$ das respostas dos participantes, seguida da institucional, com $26,6 \%$ e, em último lugar, aparece a variável clínica, com $19,1 \%$ das respostas. Ressaltamos que, no questionário, o profissional deveria marcar com um $X$ a modalidade de atuação, de forma a identificar e especificar os objetivos e estratégias de ação. Dentre as opções apresentadas, estavam: Formação de professores; Assessoria às escolas; Avaliação psicológica; Atendimento clínico.

Os dados apresentam índices interessantes quanto à modalidade de atuação, pois, na variável institucional (1), $62,1 \%$ dos participantes marcaram a opção assessoria às escolas e $52,6 \%$ marcou formação de professores. Na variável clínica (2), 87,4\% dos participantes marcaram a opção avaliação psicológica e 37,9\% marcaram o atendimento clínico. Comparando os dados entre as opções na variável, encontramos o maior índice de avaliação psicológica sobrepondo o atendimento clínico e, na outra variável, a assesso- ria às escolas com maior índice em relação à formação de professores.

Comparando os dados coletados quanto à avaliação psicológica, Souza e Silva (2009) apresentam que, no Estado de Minas Gerais, a opção teve um índice de $77,77 \%$ das respostas e, em São Paulo, o índice foi de 45,45\%, sendo que, no Paraná, tivemos $87,4 \%{ }^{5}$. Diante disso, podemos concluir que, entre esses Estados brasileiros, o Paraná é um Estado que se destaca em avaliação psicológica, isso porque, muitas vezes, o profissional é contratado justamente para avaliar. Em São Paulo, a opção que se destacou foi formação de professores, com $65,65 \%$ das respostas, e, em Minas Gerais, o destaque ficou para a assessoria às escolas, com $88,88 \%$.

Esses dados podem ser confrontados com a defesa de Yazlle (1997) de que, historicamente, ao avaliar, a Psicologia esteve comprometida com a ordem e o controle, preocupando-se com padrões gerais de comportamento medidos estatisticamente. Indo ao encontro dessas ideias, Patto (1984) declara que a primeira função desempenhada pelos psicólogos junto aos sistemas de ensino foi avaliar e classificar os alunos, como vimos anteriormente.

Ao retomar essas ideias na história da Psicologia, verificamos que o papel desempenhado pelo psicólogo escolar, conforme Maluf (1994), seria de psicometrista, ao avaliar e redigir laudos psicológicos apontando distúrbios e incapacidades comprovados cientificamente.

Nesse contexto, Facci, Leal, Barroco e Silva (2010) trazem como informação para a compreensão do trabalho de avaliação psicológica pelo profissional da Psicologia no Estado do Paraná a Deliberação N. ${ }^{\circ}$ 02/03 (Paraná, 2003), aprovada no Estado em 02/06/03. Essa deliberação estabelece normas para a Educação Especial, modalidade da Educação Básica para alunos com necessidades educacionais especiais, no Sistema de Ensino do Estado do Paraná, e determina que uma equipe multiprofissional faça avaliação do aluno para que este possa frequentar a Classe Especial ou Escola Especial; nessa equipe, o psicólogo deve estar presente. As autoras mencionam que tal deliberação acaba servindo de apoio para a inclusão do psicólogo nas escolas.

As autoras também mencionam a INSTRUÇÃO N. ${ }^{\circ}$ 011/08 - SUED/SEED (Paraná, 2008), que define os critérios para o funcionamento da Sala de Recursos das séries iniciais do Ensino Fundamental na área dos Transtornos Globais do Desenvolvimento. Essa Instrução apresenta a exigência de que o aluno a ser encaminhado para essa modalidade de ensino tenha sido submetido à avaliação psicoeducacional, processo avaliativo no qual o psicólogo deve fazer parte da equipe.

As autoras analisam que estes documentos auxiliam a contratação dos psicólogos escolares pelas Secretarias de Educação, por um lado, e, por outro, já definem, de antemão, que este deverá fazer avaliação. Essa informação pode ser constatada no relato do questionário de uma profissional ao

5 É importante ressaltar a limitação do instrumento questionário, pois nem todos os participantes descreveram que meios e recursos utilizam para a realização dessas avaliações. 
escrever no item sobre a avaliação psicológica o objetivo dessa atividade: "Emitir parecer psicológico para o ingresso do aluno na sala de recursos".

Quando categorizamos as respostas na variável clínica, relacionada à avaliação psicológica, cabe destacar que, na nossa forma de organização, não investigamos como essa avaliação psicológica era realizada. É importante mencionar que fazer avaliação psicológica nem sempre denota um modelo de intervenção clínica, pois esta dependerá da forma que está sendo realizada essa avaliação, dos instrumentos utilizados e dos personagens envolvidos no processo de avaliação, entre outros fatores.

Com relação aos projetos desenvolvidos pelos profissionais, encontramos a soma total de 104 projetos, dentre os quais tiveram maior frequência: o acompanhamento de professores, com $18,3 \%$ das respostas, seguido de grupos de adolescentes, com $17,3 \%$, da orientação de pais, com $16,3 \%$, e também da inclusão, com 15,4\%. Esses dados indicam que os profissionais estão empenhados em promover projetos que envolvam a comunidade escolar, deixando de lado a postura de desenvolver apenas atividades direcionadas ao aluno.

$\mathrm{Na}$ parte do questionário em que foi solicitado aos profissionais que citassem os autores que têm auxiliado na fundamentação teórica do trabalho, foram obtidos os seguintes dados: $51,7 \%$ citaram autores da Educação; $37,9 \%$ citaram autores da área de Educação e clínica e 5,7\% mencionaram autores da área clínica. Diante desses dados, observamos que praticamente metade dos psicólogos direciona sua prática baseados em autores da Educação. $O$ autor que teve a maior parte da citação dos profissionais $(50,5 \%)$ foi L. S. Vigotski, sendo encontrado, na sequencia, Jean Piaget, com $30,5 \%$ das citações. Se analisarmos a história das tendências pedagógicas, principalmente a partir da década de 1980, percebemos que são estes dois autores os mais utilizados para fundamentar a prática pedagógica, com destaque para a Epistemologia Genética de Piaget, que, desde a Escola Nova, tem norteado políticas educacionais.

$\mathrm{Na}$ análise dos questionários, observamos que alguns participantes listaram autores os quais identificamos estar em posições antagônicas acerca da visão de mundo e de proposta de trabalho, como, por exemplo: "Piaget, Emilia Ferreiro, Içami Tiba"; "Skinner, Patto, Emilia Ferreiro, Bandura"; "Paulo Freire, Ana Bock, Assron Beck, Tânia Zagury, Içami Tiba, Piaget". Neste sentido, percebemos que, muitas vezes, o ecletismo impera entre os profissionais, não se observando as bases filosóficas e epistemológicas dos autores mencionados. Isto pode ser apontado na junção entre Piaget e Vigotski. É importante atentar que encontramos 23 profissionais $(24,2 \%)$ que incluíram Vigotski e Piaget juntos em suas citações, o que indica a intenção dos participantes em considerar os dois autores como base teórica para o seu trabalho. Essa postura teórico-metodológica, segundo as defesas de Duarte (2007) e Facci (2004), sinaliza certa incoerência, considerando que são duas propostas pedagógicas antagônicas.
Duarte (2007) menciona que as características dos referidos autores se diferem na medida em que Vigotski possui uma abordagem historicizadora do psiquismo humano, ou seja, o psiquismo humano "não pode ser compreendido se não for abordado enquanto um objeto essencialmente histórico" (Duarte, 2007, p. 84), enquanto que, no modelo epistemológico de Piaget, o psiquismo humano é abordado de forma biológica, que "não dá conta das especificidades desse psiquismo enquanto um fenômeno histórico-social".

Embora não desconsideremos a importância de Piaget e sua teoria para a história da Psicologia, ao observar os dados coletados, podemos supor que a utilização de Vigotski pela maioria dos profissionais como o autor que embasa seus trabalhos pode ser o indício de que mudanças estão acontecendo, ou seja, o foco da intervenção que, por hora, era centrada no biológico e no indivíduo está sendo repensada.

Finalizando a análise dos questionários, foram criadas categorias para observar até que ponto era possível denotar elementos de crítica na atuação dos psicólogos. De acordo com as respostas dos profissionais, estabelecemos um número para a posterior inclusão de sua resposta no banco de dados do Software SPSS, sendo: 1 - Crítico; 2 - Não crítico; 3 - Crítico e Não crítico. Ao categorizar as respostas, levamos em conta a descrição do profissional quanto à sua atuação, observando os autores citados e as atividades desenvolvidas descritas na modalidade de atuação. As descrições que incluem autores considerados da Psicologia Crítica, com um olhar de atuação da Psicologia no contexto escolar que ultrapassa uma compreensão individualizante dos fatos foram incluídos na perspectiva crítica de atuação, inclusive os que mencionaram a Psicologia Histórico-Cultural e a base teórico-metodológica da Psicologia Marxista. Os profissionais que tiveram descrição clara de atividade que remetem à Psicologia Tradicional, com ações envolvendo aplicação de testes e atendimento individual, foram incluídos na perspectiva não crítica (2). Para o item (3), crítico e não crítico, incluímos as respostas cujas descrições perpassam por uma perspectiva e outra. Estes profissionais, poderíamos dizer, ao mesmo tempo em que trazem elementos de crítica em suas respostas ou intervenções, por outro lado, mantêm concepções e práticas também presentes em uma visão tradicional, como se estivessem em um processo de transição entre uma visão ou outra.

As respostas coletadas nos questionários estiveram mais evidentes no discurso não crítico, com $54,3 \%$ das respostas, seguidas do discurso crítico e não crítico, com $27,2 \%$. Em último lugar, aparece o discurso crítico, com $18,5 \%$ das respostas, evidenciando o tipo de atuação e formação que os profissionais estão desenvolvendo no seu cotidiano. Considerando que o termo crítico e não crítico é o foco para a análise, propomos a retomada de alguns elementos, os quais caracterizam essa forma de atuação.

Meira (2000) remete à necessidade de não corrermos o risco de banalizar o conceito de crítica, considerando que é um conceito que pode ter diferentes significados em decorrência da posição teórico-filosófica adotada. Neste sentido, 
a autora propõe a análise de alguns elementos que considera imprescindíveis, pois são constitutivos do pensamento crítico, a saber: reflexão dialética, crítica do conhecimento, denúncia da degradação humana e a possibilidade de ser utilizado como um instrumento de transformação social.

Nesta direção, é preciso alcançar rigor para situar o conhecimento indo até sua raiz e não apenas recusar um conhecimento em nome do outro. A autora define "ir até a raiz" como: "[...] definir os seus compromissos sociais e históricos, localizar a perspectiva que o construiu, descobrir a maneira de pensar e interpretar a vida social da classe que apresenta esse conhecimento como universal” (pp. 40-41).

Partindo desse pressuposto, alguns elementos podem ser observados na prática do psicólogo, que, de acordo com Meira (1997), são considerados indicativos do pensamento crítico na atuação do psicólogo escolar condizente à concepção de base marxista: como o psicólogo compreende o fracasso escolar? Quais as áreas de intervenção escolhidas? Qual o modelo de atuação no qual o trabalho se assenta? Como são utilizados os processos de avaliação das queixas escolares? Quais os vínculos que o profissional estabelece com a comunidade escolar? Todas essas questões sinalizam para a forma como o profissional compreende o fenômeno e como direciona sua atuação na busca da superação do problema.

Concordamos com a referida autora e encontramos Tanamachi e Meira (2003), que também incluem, como fatores que caracterizam uma concepção crítica em Psicologia, a referência teórico-filosófica e metodológica ao Materialismo Histórico Dialético. Segundo as autoras, essa perspectiva teórica dá um enfoque "[...] nas categorias que têm implicações imediatas para a compreensão do processo de humanização dos indivíduos no contexto sócio-histórico atual" (Tanamachi e Meira, 2003, p.18), destacando Marx, Lucian Sève, Lev Semynovich Vygotsky e Alexei Nikolaievich Leontiev como os autores que embasam essa concepção.

Ao levarmos em conta as respostas apresentadas na categoria não crítico, vamos encontrar elementos que retomam as características marcantes iniciais da Psicologia Escolar: a patologização dos problemas escolares, a culpabilização das crianças e suas famílias pelo sucesso ou fracasso, assim como o foco nos problemas emocionais como a causa dos problemas de aprendizagem, levando a uma psicologização do contexto escolar.

Gostaríamos de ressaltar que, na pesquisa, não intentamos enquadrar o trabalho desenvolvido pelos profissionais em crítico ou não crítico, mas sim destacar o processo de transição que observamos no trabalho dos psicólogos participantes da pesquisa, o que nos faz pensar que, enquanto categoria, estamos repensando nossa prática e buscando novas alternativas para superar uma atuação guiada exclusivamente por preceitos biológicos - da Medicina - ou guiados por medidas de avaliação da inteligência - pela Psicometria.
Consideramos que a pesquisa possibilitou o conhecimento acerca da atuação dos psicólogos do Paraná. Constatamos que existe um número expressivo de psicólogos trabalhando na Educação no Estado do Paraná e que está havendo uma ampliação dos serviços. Os dados obtidos com a pesquisa são atuais e inéditos, pois não existe um banco de dados referente ao trabalho do psicólogo neste Estado, nem por meio das Secretarias de Educação, nem pelo CRP. Nossa intenção é que esses dados possam suscitar novas discussões sobre o trabalho a ser desenvolvido pelos profissionais, assim como promover o interesse dos municípios que ainda não têm o trabalho desenvolvido pelo profissional, pois, em nosso entendimento, tal trabalho se justifica como possível e necessário.

Como já afirmamos, longe de rotular os psicólogos paranaenses, temos que compreender o porquê das respostas que conduzem, ainda, a uma visão clínica da atuação do psicólogo escolar. Temos que pensar que um dos fatores que contribui para tais respostas remete à formação destes profissionais. Há de se considerar que os cursos de formação precisam ser revistos para que ocorra essa superação, pois, segundo Souza e Silva (2009, p. 102), "[...] não apenas porque os cursos de graduação nem sempre conseguem formar profissionais críticos, mas também porque a prática cotidiana precisa andar de mãos dadas com o conhecimento produzido nos principais centros de pesquisa". Em uma década na qual temos que, a todo instante, nos posicionar contra a medicalização do escolar, fica evidente o quanto ainda é forte uma visão organicista para explicar os problemas de escolarização. Fica evidente, também, o quanto estamos sendo guiados pelo ideário liberal que atribui aos indivíduos a responsabilidade pelo fracasso ou sucesso escolar.

Não podemos deixar de analisar que o contexto social, em uma sociedade de classes, produz explicações que levam à manutenção da sociedade da forma que está; nesse sentido, quando falamos de transformação, mesmo que seja na forma de avaliar e encaminhar as queixas escolares, isso se torna bastante complicado, pois remete à necessidade de análise das condições histórico-sociais que estão produzindo, cada dia mais, escolas esvaziadas de conhecimento e psicólogos que consideram que, realmente, a culpa do não aprender está no aluno, no professor e nos pais. Tal contexto pode explicar o posicionamento dos psicólogos entrevistados que, em alguns momentos, parecem apresentar elementos de crítica e, em outros, não, em um processo de transição no qual contradições se apresentam na prática e compreensão das queixas escolares.

Considerando, ainda, que estamos vivendo um momento histórico no qual novas expressões são valorizadas e as pessoas sofrem dessa influência, intensificando a tendência de usar também os termos que estão na moda, concordamos com Meira (2000) quando afirma que é possível verificar a tendência atual, a moda que invadiu o campo da Psicologia em abordá-la sob uma visão crítica e comprometida com a finalidade de transformação, no entanto, o que se pode observar é o desconhecimento de uma fundamentação teórica que permita o entendimento histórico de uma socie-

\section{Consideraçoes Finais}


dade em transformação e povoada de contradições. Assim, coadunamos com a defesa de Tanamachi e Meira (2003) de que, enquanto profissionais, precisamos ter essa clareza e elencar elementos e aspectos que indicam o que estamos realmente atribuindo à postura crítica de atuação. Não basta anunciar uma visão crítica; é necessário empreender ações para que isso aconteça. Concordamos com Meira (2000) quando ela afirma que "É preciso estar atentos para não incorrermos no risco de simplesmente adotar o discurso da transformação sem alcançarmos a consistência teórica e filosófica necessária para concretizá-la" (Meira, 2000, p. 54).

Facci (1991) defende que, para os profissionais envolvidos com a educação e com a formação de pessoas, seria importante repensar a crise que abala a escola, seus insucessos e a relação que se estabelece com a crise e insucessos na sociedade capitalista. A autora afirma que o centro da questão, portanto, é utilizar um método histórico para compreender essa crise, capaz de captar todas as contradições da sociedade capitalista; se a escola "vai mal", é porque a sociedade não está dando conta de lidar com todos os problemas presentes. A escola, a cada dia, está perdendo mais sua função de ensinar.

Retomando o que afirmamos anteriormente, de acordo com a Psicologia Histórico-Cultural, a educação é fundamental para que o homem se humanize. Assim, estamos na defesa de que a escola deve criar condições para que o aluno tenha o desenvolvimento pleno de suas potencialidades, pois é função da escola, segundo Saviani (2003), socializar os conhecimentos, tornando individualizados os conhecimentos produzidos pela humanidade no processo histórico. Entendemos, assim como Facci (2009), que é pelo conhecimento que esse sujeito pode desvelar a realidade e buscar a transformação da sociedade em que vive, uma vez que a escola pode contribuir para a transformação da consciência dos alunos.

Para que professor e psicólogo consigam ter essa clareza da função da escola no processo de humanização dos alunos, precisam valorizar a necessidade de um aprofundamento teórico, conforme indica Facci (2009), pois somente se apropriando dos conhecimentos já produzidos pelo homem, ou seja, antes sendo humanizados, poderão humanizar o aluno. Facci (2009) enfatiza a função que a Psicologia tem a essa humanização na escola, utilizando os espaços de formação e atuação docente na direção a cumprir essa função e tratando de temas nessa formação, como: o fracasso escolar, as queixas escolares, a periodização do desenvolvimento humano, indisciplina, violência, afetividade, aprendizagem etc. Humanização, neste sentido, relacionada à apropriação dos conhecimentos produzidos pela Psicologia e áreas afins para compreender os fenômenos escolares e o desenvolvimento do psiquismo.

Como afirma Shuare (1990), o historicismo é a chave para compreender o psiquismo do homem. É esse preceito, do nosso ponto de vista, que deve guiar a prática dos psicólogos escolares quando lidam com as queixas escolares e pautam-se nos pressupostos da Escola de Vigotski. Fundamentalmente, o que se espera dos profissionais que têm uma perspectiva crítica de atuação, a partir dos pressupostos vigotskianos, é que rompam com as explicações pseudocientíficas que buscam a origem dos problemas educacionais no aluno ou em sua família. Os processos tradicionais de avaliação e diagnóstico centralizados no aluno não dão conta de responder os aspectos que estão por trás do problema. É preciso, portanto, compreender o homem concreto, síntese das relações sociais.

Diante do exposto, defendemos a necessidade de o psicólogo contribuir com o seu conhecimento ao desenvolver um trabalho orientado teoricamente de forma consistente, com clareza dos fundamentos teóricos, em detrimento do ecletismo. A meta é entender o indivíduo concreto, síntese das relações sociais, conforme apregoa a visão marxista.

\section{Referências}

Antunes, M. A. M. (2007). A Psicologia no Brasil: Leitura Histórica Sobre sua Constituição. São Paulo: UNIMARCO e EDUC.

Conselho Estadual de Educação do Paraná. (2003). Deliberação $n^{\circ}$. 02/03. Estabelece normas para a Educação Especial, modalidade da Educação Básica para alunos com necessidades educacionais especiais no Sistema de Ensino do Estado do Paraná. Curitiba, Paraná.

Duarte, N. (2007). Educação escolar, teoria do cotidiano e a escola de Vigotski ( $4^{a}$ edição). Campinas, SP: Autores Associados.

Facci, M. G. D. (1991). A reprodução do modo capitalista de explicar o fracasso escolar - uma reflexão preliminar. Monografia da Especialização em Psicanálise e Materialismo Histórico, Universidade Estadual de Maringá, Maringá, Paraná.

Facci, M. G. D.(2004). Teorias educacionais e teorias psicológicas: em busca de uma Psicologia marxista da educação.Em N. Duarte (Org.), Crítica ao fetichismo da individualidade (pp. 99-120). Campinas, SP: Autores Associados

Facci, M. G. D. (2007). Professora, é verdade que ler e escrever é uma coisa fácil? - Reflexões em torno do processo ensinoaprendizagem na perspectiva vigotskiana. Em E. M. Meira \& M. G. D. Facci (Orgs.), Psicologia histórico-cultural: Contribuições para o encontro entre a subjetividade e a educação (pp. 135-156). São Paulo: Casa do Psicólogo.

Facci, M. G. D. (2009). A intervenção do psicólogo na formação de professores: contribuições da Psicologia Histórico-Cultural. Em C. M. M. Araújo (Org.), Psicologia Escolar: novos cenários e contextos de pesquisa, formação e prática (pp. 107-131). Campinas, SP: Editora Alínea.

Facci, M. G. D., Leal, Z. F. R. G., Barroco, S. M. S., \& Silva, V. G. (2010). A atuação do psicólogo na rede pública de educação frente à demanda escolar: concepções, práticas e inovações. Relatório de Pesquisa. Maringá 
Leontiev, A. N. (1978). O desenvolvimento do psiquismo. Lisboa: Livros Horizonte.

Machado, A. M. (1997). Avaliação e fracasso: a produção coletiva da queixa escolar. Em J. G. Aquino, Erro e fracasso na escola: alternativas teóricas e práticas (pp. 73-79). São Paulo: Summus.

Machado, A. M. (2010). Medicalização e escolarização: por que as crianças não aprendem a ler e escrever? Em Conselho Regional de Psicologia de São Paulo (Org.), Dislexia: subsídios para políticas públicas (pp. 24-29). São Paulo: CRPSP.

Machado, A. M., \& Souza, M. P. R. (1997). As crianças excluídas da escola: um alerta para a psicologia. Em A. M. Machado \& M. P. R. Souza (Orgs.), Psicologia Escolar: em busca de novos rumos. São Paulo: Casa do Psicólogo.

Maluf, M. R. (1994). Formação e atuação do psicólogo na educação: dinâmica de transformação. Em Conselho Federal de Psicologia, Psicólogo brasileiro: práticas emergentes e desafios para a formação (pp. 157-200). São Paulo: Casa do Psicólogo.

Maluf, M. R. (2006). Psicologia Escolar: novos olhares e o desafio das práticas. Em S. F. C. Almeida (Org.), Psicologia Escolar: ética e competência na formação e atuação profissional. Campinas, SP: Editora Alínea

Markus, G. (1974). Teoria do Conhecimento no Jovem Marx. Rio de Janeiro: Paz e Terra.

Meira, M. E. M. (1997). Psicologia Escolar: pensamento crítico e práticas profissionais. Tese de Doutorado, Instituto de Psicologia, Universidade de São Paulo, São Paulo.

Meira, M. E. M. (2000). Psicologia Escolar: pensamento crítico e práticas profissionais. Em E. R. Tanamachi, M. L. Rocha, M. R. Proença (Orgs.), Psicologia e Educação: desafios teórico-práticos (pp. 35-72). São Paulo: Casa do Psicólogo.

Meira, E. E. M, \& Antunes, M. A. M. (Orgs.). (2003). Psicologia Escolar: Teorias Críticas. São Paulo: Casa do Psicólogo.

Meira, E. M. (2003). Construindo uma concepção crítica de Psicologia Escolar: contribuições da pedagogia histórico-crítica e da psicologia sócio histórica. Em M. E. M. Meira \& M. A. M. Antunes, Psicologia Escolar: teorias críticas. São Paulo: Casa do Psicólogo

Moysés, M. A. A., \& Collares, C. A. L. (1997). Inteligência abstraída, crianças silenciadas: as avaliações de inteligência. Psicol. USP, 8(1), 63-89.

Patto, M. H. S. (1984). Psicologia e Ideologia: uma introdução crítica à psicologia escolar. São Paulo: T. A. Queiroz
Proença, M. (2002). Problemas de aprendizagem ou problemas de escolarização? Repensando o cotidiano escolar à luz da perspectiva Histórico-Crítica em psicologia. Em M. K. Oliveira, T. C. Rego \& D. T. R. Souza (Orgs.), Psicologia, Educação e as temáticas da vida contemporânea (pp. 177-195). São Paulo: Moderna

Saviani, D. (2003). Pedagogia Histórico-Crítica: primeiras aproximações (8 $8^{\mathrm{a}}$ Edição). Campinas, SP: Autores Associados.

Saviani, D. (2004). Perspectiva marxiana do problema da subjetividade -intersubjetividade. Em N. Duarte, Crítica ao fetichismo da individualidade (pp. 21-52). Campinas, SP: Autores Associados.

Shuare, M. (1990). La psicología soviética tal como yo la veo (pp. 5785). Moscou: Editorial Progresso.

Souza, B. P. (2007). Apresentando a orientação à queixa escolar. Em Souza, B. P. (Org.), Orientação à queixa escolar. São Paulo: Casa do Psicólogo.

Souza, M. P. R., \& Silva, S. N. C. (2009). A atuação do psicólogo na rede pública de educação frente à demanda escolar: concepções, práticas e inovações. Em C. M. M. Araújo (Org.), Psicologia Escolar: novos cenários e contextos de pesquisa, prática e formação. Campinas, SP: Editora Alínea (Coleção Psicologia Escolar).

SUED/SEED. Instrução $n^{\circ}$ 011/08. (2008). Define os critérios para o funcionamento da Sala de Recursos das séries iniciais do Ensino Fundamental na área dos Transtornos Globais do Desenvolvimento. Curitiba, Paraná.

Tanamachi, E. R., \& Meira, M. E. M. (2003). A atuação do psicólogo como expressão do pensamento crítico em psicologia e educação. Em E. E. M. Meira \& M. A. M. Antunes (Orgs.), Psicologia Escolar: práticas críticas. São Paulo: Casa do Psicólogo.

Vasconcelos, M. S. (1996). A difusão das idéias de Piaget no Brasil (L. de Macedo, coord.). São Paulo: Casa do Psicólogo (Coleção Psicologia e Educação).

Vigotski, L S. (2000). A construção do pensamento e da linguagem. São Paulo: Martins Fontes

Yaslle, E. G. (1997). Atuação do psicólogo escolar: alguns dados históricos. Em B. B. B. Cunha e cols., Psicologia na escola: um pouco de história e algumas histórias. São Paulo: Arte \& Ciência. 
Recebido em: 07/02/2011

Reformulado em: 29/04/2011

Aprovado em: 27/05/2011

\section{Sobre as autoras}

Patrícia Vaz de Lessa (patricia.lessa@unifil.br)

Universidade Estadual de Maringá - UEM

Psicóloga, Pedagoga, Especialista em Metodologia da Ação Docente, Mestre em Psicologia pela Universidade Estadual de Maringá - UEM.

Docente do Departamento de Psicologia do Centro Universitário Filadélfia - Unifil.

Marilda Gonçalves Dias Facci (mgdfacci@uem.br)

Universidade Estadual de Maringá

Doutora em Educação Escolar pela UNESP-Araraquara, professora do Departamento de Psicologia e Programa de Pós-Graduação em Psicologia da Universidade Estadual de Maringá.

Agradecimento a Fundação Araucária - Apoio ao Desenvolvimento Científico e Tecnológico do Estado do Paraná pelo apoio financeiro destinado à pesquisa. 